\title{
Can Simulated Data be Comparable to Authentic Data?: A Comparative Analysis of Meeting Chairing Activities
}

\author{
Bertha Du-Babcock', Angela Chi Kuen Chan² \\ ${ }^{1}$ City University of Hong Kong, Hong Kong, China \\ ${ }^{2}$ Shantou University, Guangdong, China
}

Objectives: This paper examines an under-researched issue - the comparability between authentic and simulated data, both of which are commonly used in business and professional communication. By analysing face-to-face business meetings, this paper aims to investigate (1) whether the four meeting chairing activities are accomplished in similar or different ways in authentic and simulated meetings?, and (2) under what settings simulated data would be comparable to authentic data for business and professional communication research.

Methods: The study employs a fine-grained discourse-analytic approach to examine and compare four meeting chairing/facilitation activities (i.e., meeting opening, agenda management, turn allocation, meeting closing) in two authentic and two simulated business meetings.

Results: Analysis shows that simulated meetings display a considerable degree of similarities to authentic meetings in terms of communicative strategies used to open or close a meeting, to manage the meeting agenda, and to allocate speakership while differences are observed in the actual discourse used to accomplish these chairing activities. The observed differences can be attributed in terms of the participants' orientations to the meetings' contextual factors including the setting that a simulated meeting is embedded, the organizational roles that a meeting chair is playing, and the relationship among the meeting participants.

Conclusion: Findings suggest that simulated data can be compatible for studying communicative patterns at macro-levels although it may not be suitable for researching business communication at a micro-level of interaction. We also provide implications of using simulated data for conducting research in business communication.

Key Words: Simulated Data, Authentic Data, Face-to-Face Business Meetings, Meeting Chairing, Comparability between Authentic and Simulated Data

Received: Feb 21, 2019 Revised: Mar 26, 2019 Accepted: Mar 29, 2019 Corresponding author: Angela Chi Kuen Chan Department of Foreign Languages and Literature, College of Liberal Arts, Shantou University, 243 Daxue Road, Shantou, Guangdong, China. Tel: +86-754-86503677, E-mail: angela@stu.edu.cn

This is an Open Access article distributed under the terms of the Creative Commons Attribution Non-Commercial License (http://creativecommons.org/licenses/ by-nc/4.0/) which permits unrestricted non-commercial use, distribution, and reproduction in any medium, provided the original work is properly cited.

Copyright $(9) 2019$ Korean Association for Business Communication.

\section{Introduction}

Simulation as an educational tool has grown considerably for about half century and has been considered a high impact immersive learning tool and a central mode of instruction in the training of, among other professionals, future business executives (e.g., Faira, Hutchinson, Wellington, \& Gold, 2009) and the education of business communication (e.g., Du-Babcock \& Babcock, 2000). Scholars who advocate that simulation recre- 
ates characteristics of the real world (Beaubien \& Baker, 2004) believe that simulation allows the trainer to carefully control the learning environment and to optimize conditions for the skills being taught. They also argue that the rise of simulation as an instructional tool counters the criticism that today's education has been theory driven, lacking a component of critical thinking, creativity and innovation (e.g., Ben-Zvi \& Carton, 2008; Hughes, O’Regan, \& Wornham, 2008; Snyder \& Snyder, 2008). This group of scholars also think that simulation as a learning tool replicates and amplifies significant aspects of the real world in a fully interactive fashion while protecting young professionals or students from unnecessary risks, and acquiring the knowledge in a safe learning environment (see, for example, Lateef, 2010). Therefore, well-designed simulation activities provide structured learning experiences, and measure predetermined competencies and learning objectives. In other words, a well-designed simulation "simplifies a real world system while heightening awareness of the complexity of that system" (Chilcott, 1996, p. 3), enabling students to experience and test drive in situations before encountering a real life experience. It is believed that through the "hands-on" experiential exercise, simulation enhances deep learning (Hertel \& Millis, 2002) which is a crucial step to altering a learner's mental model, facilitating the process of unlearning and relearning (see for example, Riedel \& Hauge, 2011).

Although simulation as an instructional approach has widely adopted since 1950s and a great number of studies examining the effect of simulations has shown a positive educational impact (e.g., Cook, Erwin, \& Triola, 2010; Cooper et al., 2012; Lorello, Cook, Johnson, \& Brydges, 2014), there has been a constant debate in recent years as to whether the simulated data can be comparable with the authentic data, as discussed in the following section.

\section{Controversy over the Authenticity of Simulated Data}

The question of whether simulated data can reflect genuine practices of the real world of business has been debated for decades. Researchers confronting the authenticity of the simulated data argue that interaction produced in natural settings is more complex and contains more turns and sequences than that produced in simulated settings (Beebe \& Cummings, 1996; Eisenstein \& Bodmon, 1993; Kasper, 2000). Firth (1995) criticizes that simulated data is produced in a decontextualized environment and many characteristics of simulated data are unusual in real-life encounters (e.g., all participants share similar backgrounds). White and Casey (2016) compared the interaction in actual and simulated surgical consultations and point out that medical problems are presented differently by actors in simulat- ed consultations and patients in actual consultations.

Participants' orientations to the simulated setting have been attributed to the differences found in simulated and authentic data. Stokoe's (2013) study comparing role-played and actual interviews by police officers reveals that many actions in simulated interviews are accomplished in more explicit and elaborative manners than those in actual interviews. She attributes the finding to the fact that the officers in simulations "are being assessed" (p. 182). Similarly, in a comparative study of direction giving in gas stations, Ewald's (2012) study reveals that the directions given in authentic settings tend to have more details (such as landmarks, mileage estimates) but contain more errors while the role-play participants' directions tend to be more accurate but contain fewer details. Due to "the absence of real-world consequences" (Ewald, 2012, p. 94), role-play participants appear to be more concerned about being good research participants rather than giving detailed directions.

On the contrary, researchers who regard simulated data are comparable to authentic data support that simulation enables research to be conducted in an "artificially created but not too different from reality" environment (Sekaran \& Bougie, 2014, p. 188). Planken (2002, cited in Bargiela-Chiappini, Nickerson, \& Planken, 2013, p. 17) contends that simulated data "serves as the best alternative" to authentic data. Similarly, White (1997, p. 322) concludes that "participants [in simulated negotiations] do not radically alter their communication style and language in 'real' situations". While the goal of a simulated interaction is predetermined, the participants have to accomplish the actions through talk, and hence the interaction per se is spontaneous and locally managed by the participants (Kasper, 2000), and can demonstrate various communicative features which are also observed in natural interaction (Félix-Brasdefer, 2010). This group of researchers also argue that the negative impact of the simulated setting is temporary and can be minimized when experienced practitioners are recruited (Ulijn, 2000). Moreover, simulation enables researchers to repeat the same activity with different combinations of participants so that researchers can develop a more general picture of the research activity and test the cause and effect relationship between dependent and independent variables (Félix-Brasdefer, 2010; Sekaran \& Bougie, 2014; van der Wijst \& Ulijn, 1995).

The above review shows that there are different views towards the validity of using simulated data for research purposes, yet few studies have been conducted to investigate its compatibility to authentic data. Against this background, the present study aims to conduct a comparative study to explore the extent to which interaction in simulated data can manifest authentic practices in the business world. Particularly, the present study 
examines meeting chairing activities in face-to-face business meetings, where participants are physically present at the same location, conducted in two settings, namely, the authentic setting and the research simulation setting. In the latter setting, experienced business professionals are recruited as participants and assigned certain professional roles which are different from their own in their workplace; they are required to accomplish a task that mimics a business-like scenario in a workplace environment.

We next review the relevant studies on meeting chairing activities in face-to-face business meetings. Specifically, it reviews characteristics of meeting chairing (or meeting facilitation) activities and the impact of situational contexts on meeting chairing.

\section{Characteristics of Meeting Chairing/Facilitation Activities}

Previous studies (e.g., Boden 1994; Holmes \& Stubbe, 2015; Pomerantz \& Denvir, 2007) have pointed out that in face-toface meetings, activities that index meeting chairing include (1) declaring the meeting opening, (2) setting the agenda and moving from one item to another one, and (3) allocating speaking turns, and adjourning the meeting. Each of these activities possesses distinctive communicative characteristics as illustrated in the following.

\section{Meeting Openings}

A meeting opening marks the start of the meeting and signals to the participants from the moment onward they are expected to conform to the communicative conventions in the meeting setting (Boden, 1994; Nielsen, 2013). Once the chairperson initiates the opening of the meeting, the speaking floor is usually governed by the chair and mostly one speaker is allowed at a time (Boden, 1994; Sacks, Schegloff, \& Jefferson, 1974) (see also below the section on turn allocation). A meeting opening is usually accomplished in a sequence of actions. The opening sequence can be initiated by verbal actions such as attendance assessment and enumeration of the agenda (Boden, 1994), non-verbal actions such as closing the door of the meeting room (Chan, 2008) and eye gazing (Oittinen \& Piirainen-Marsh, 2015), silence (Nielsen, 2013), as well as a transitional marker with marked pronunciation features (e.g., lengthened, stressed, increased volume; Atkinson, Cuff, \& Lee, 1978). These initiations prepare the participants to shift their orientation from pre-meeting conventions to meeting conventions. Moreover, a topic transitional marker (e.g., okay, all right, so) is often used to mark a shift from the pre-meeting talk to the meeting talk (Boden, 1994). Such a topic transitional marker may be followed by an explicit declaration of opening such as Let's get started (Boden, 1994) and/or an introduction to a meeting-re- lated item (Chan, 2008, 2017).

\section{Agenda Management}

Agenda management can be realized through deciding what is to be discussed and in what order, introducing an item on the agenda, and shifting from one agenda item to the next one (Asmuss \& Svennevig, 2009). In a formal meeting, a written agenda is usually prepared and circulated to the participants in advance and is used to guide the meeting discussion. However, there usually is "room for the variation in how strictly the chair will control the topic by reference to the agenda or allow the topic to be locally managed” (Asmuss \& Svennevig, 2009, p. 15).

\section{Turn Allocation}

Turn allocation is locally managed by the participants through three techniques: self-selection, the current speaker's selection of the next speaker, and the current speaker's continuation (Sacks et al., 1974). In any meeting turn allocation is often regulated by mixed turn-taking systems ranging from a conversation-like system to a chair-controlled system (Asmuss \& Svennevig, 2009). According to Boden (1994), formal meetings tend to demonstrate a controlled and restricted nature of turn-taking while informal meetings exhibit more features of conversation-like turn allocation techniques.

\section{Meeting Closings}

Meeting closings signal to the meeting participants the moment from which they can shift their orientation from the communicative conventions for a meeting to the conventions for mundane conversation (Boden, 1994; Chan, 2008; Nielsen, 2013). A meeting closing can be achieved through several steps. It may be initiated with a noticeable pause plus a transitional marker (e.g., okay) and a request for any other business (e.g., anything else?). If new business is brought up, the meeting will move backwards to the discussion section. The steps are repeated until no new business is brought up. The chair will then indicate the close of the meeting by giving a formal declaration (e.g., Let's adjourn) or an expression of appreciation (e.g., thank you) (Boden, 1994; Chan, 2008). Finally, intensified background noise and split conversations reappear and the participants get ready for departure (Chan, 2008).

In sum, it is evident that business meetings possess distinctive characteristics and are commonly practiced in the business world. They constitute suitable site for the present study. The four meeting activities reviewed above can be found in most business meetings and can be accomplished in a range of linguistic forms. Consequently, based on the above literature review, we put forth the following research questions (RQs): 
RQ1: Are the four meeting chairing activities (i.e., meeting opening, agenda management, turn allocation, meeting closing) accomplished in similar or different ways in authentic and simulated meetings?

RQ2: Under what settings would simulated data be comparable to authentic data for business and professional communication research?

\section{Methods}

The present study draws on two sets of business meetings selected from two large corpora collected for different but related research purposes. When each corpus was collected, the appropriate ethics procedures for research involving human participants were followed. Details about the two corpora have been well-documented in Du-Babcock (2013) and Du-Babcock and Tanaka (2013). For the sake of compatibility (explained later), two authentic meetings and two simulated meetings were selected for this study. The total length of the four meetings is about 8 hours (excluding pre-and post-meeting sections). The meetings involved 28 participants and produced approximately 5,234 turns or 69,380 words. In the following, we present the four selected meetings in detail.

\section{Research Data}

This subsection describes the two sets of meetings selected for the present study and discusses their compatibility.

\section{Authentic meetings (AMs)}

The two AMs were video-taped top management meetings from one Europe-based multinational corporation. One meeting, which is referred to as AM1 in this paper, involved the editorial team of the corporate's in-house magazine and was chaired by the chief editor. The meeting reviewed the production of the latest issue (number three) and developed a page plan for the next issue (number four) of the company magazine. The meeting was conducted in English and lasted for about 2.75 hours excluding a 15-minute coffee break.

The second meeting, AM2, was attended by the members of the corporate's human resources management team. Chaired by the team leader, AM2 discussed a variety of issues, including the on-going salary negotiations in Finland, the company's new head office in England, and a merger partner in the United States. The meeting was to provide updates on each other's work-in-progress and to make decisions on issues raised. The meeting was in English and lasted about 3.5 hours excluding a one-hour lunch break.

In each of the two meetings, a researcher was present to set up the recording equipment, change tapes and take field notes. In the beginning of the meeting, the researcher was invited to talk about the purpose of the video recording and then remained silent for the rest of the recording. The recordings show that all of the participants behaved naturally in the meetings, suggesting that the presence of the researcher and the recorders had minimal impact on the naturalness of these meetings (see also Handford, 2010; Holmes \& Stubbe, 2015).

\section{Simulated Meetings (SMs)}

The two SMs came from a research project which examines the effect of the language proficiency and culture on communication behaviors in intercultural and intracultural decision-making meetings. For SMs, the participants assumed the roles of corporate directors of a pharmaceutical company attending an urgent board meeting to deal with a company crisis (see Guffey \& Du-Babcock, 2010, pp. 461-465, for the case scenario of the simulation). The meeting participants were requested to respond to the crisis and make decisions on strategic actions that the company should take in the US and Asian markets. To facilitate the discussion, five options of strategic actions were provided. Prior to the meeting, the case scenario was sent to the participants via email and the participants were asked to study the case and choose one out of the five options for the US market and one for the Asian market. In the meeting, the participants were required to come up with a group decision for the company to issue a press release.

A research assistant was present to manage the recording equipment and the logistics. Before the meeting started, the researcher in Hong Kong welcomed the participants, introduced the research project, and invited the participants to self-introduce to each other. The researcher then handed the floor over to the participants.

For compatibility both data set of AMs and SMs were conducted in face-to-face settings, and the meetings in English were selected for the present study. All participants were business professionals with 5 to 15 years of full-time working experience, holding mid-level managerial or equivalent positions, and having experience in chairing business meetings. The meetings last for 56 minutes and 50 minutes respectively. The recordings show that throughout the meetings, the participants were engaged in the decision-making task and paid no attention to the recorders.

\section{Compatibility of the Two Sets of Meeting Data}

The two AMs and the two SMs were selected for analysis due to their compatibility in terms of formality and meeting purpose. First, all of the four meetings were conducted in face-to-face 
settings. Second, English was used as a business lingua franca, of which all participants had adequate language proficiency and interactive listening skills for business related communication (Du-Babcock, 2013). Third, all of the meetings can be classified as formal meetings (Holmes \& Stubbe, 2015) in that the meetings were (a) scheduled with predetermined participants and agenda, (b) structured with identifiable openings and closings as well as discussion sessions, and (c) chaired by designated chairs. Lastly, although the meetings had different meeting purposes, each meeting contained episodes in which the participants took turns to report their work-in-progress (in AMs) or individual opinions (in SMs), followed by discussion. During these episodes, chair-controlled turn allocation and agenda management frequently took place and constituted data for comparison in the present study.

\section{Data Analysis}

The analysis draws on principles and methods developed from the discourse analytical approaches which emphasize a moment-by-moment fine-grained analysis of the recorded meeting discourse (e.g., Asmuss \& Svennevig, 2009; Holmes \& Stubbe, 2015). In line with the discourse analytic tradition, this study adopts "an emic or participant-based" approach towards the issue of context (Svennevig, 2011, p. 20). In this study, both AMs and SMs involved a wide range of contextual variables such as institutional identity (manager, team member, board member, etc.), ethnicity (Chinese, Swede, Finn, etc.), gender (female or male), and culture (intercultural or intra-cultural settings). In analyzing the data, these contextual variables are regarded relevant and taken into consideration only when the participants make the variables relevant in their talk, i.e., only when we (researchers) can find specific evidence in the data (Svennevig, 2011).

To answer the two research questions, the present study focuses on the four meeting chairing activities: meeting opening, agenda management, turn allocation, and meeting closing. We carefully studied the transcripts and recordings of the four selected meetings, identified and coded the instances that performed one of the four activities. We then compared the turn designs and sequential placements of the coded instances to identify similar and different discursive strategies used to accomplish the meeting activities in the two types of meetings (RQ1). Based on the findings yielded from RQ1, we explored plausible factors to which the similarities and differences can be attributed so as to suggest possible settings in which simulated meetings might or might not be comparable to authentic data for research purposes (RQ2). While many factors might have influenced the running of the meetings, we focus on factors that are evident in the data or literature.

\section{Results and Discussion}

In this section, we report and interpret findings concerning our research questions.

R01: Are the Four Meeting Chairing Activities Accomplished in Similar or Different Ways in Authentic and Simulated Meetings?

RQ1 examines whether meeting chairing activities are accomplished in a similar or different manner in authentic and simulated meetings. In so doing, we compare and discuss the similarities and differences of the four meeting chairing activities between the two types of meetings. Excerpts are presented to illustrate the findings. Each excerpt is representative of the other meeting in their group. The findings are organized according to the four meeting chairing activities. Transcription conventions are provided in the appendix 1 for reference.

\section{Meeting Openings}

Across the two types of meetings, the meeting openings are accomplished similarly through a sequence of actions. Excerpts 1 and 2 illustrate the openings in the two types of meetings.

Excerpt 1 illustrates how the meeting chair, Colin, of AM2 opens the meeting. In the beginning of the video recording of the meeting, some participants are standing and talking about photos of their colleagues while others come in and put down their belonging on the meeting table. There are also indecipherable exchanges and loud laughter. The scene illustrates a typical pre-meeting scenario which could take place in any meeting. In line 1, Colin makes a humorous comment to tease at his progress of learning Finnish. The self-denigrating comment receives laughter and further teasing from other participants (lines 2-7). Up to this point, the conversation can be treated as small talk (Mirivel \& Tracy, 2005) as Colin's Finnish proficiency does not seem to have relevance to the meeting on human resources issues.

By assessing attendance and by closing the meeting room's doors (lines 8-10), Colin signals that the meeting is about to start and shifts the setting from one which allows simultaneous multiple conversations (the pre-meeting section) to another in which one speaker at a time is the norm (the meeting section) (Chan, 2008; Nielsen, 2013). During the 15-second pause in line 11 no one attempts to continue or initiate a conversation, showing the participants' readiness to conform to the meeting conventions (Nielsen, 2013). In line 12, Colin utters "well" and then brings up an issue that is relevant to the meeting. It is evident that this "well" performs the function of meeting opening and marks the transition from a conversation-like turn-taking to a meeting turn-taking (Boden, 1994). 
Excerpt 1. Opening sequence of authentic meeting 2 (AM2)

\begin{tabular}{|c|c|c|}
\hline 1 & Colin: & ((laughs)) Good learning after two years. \\
\hline 2 & Mauri: & heh heh heh \\
\hline 3 & Aarto: & Yeah (0.5) Great improvement. \\
\hline 4 & Colin: & [Mm Mm ] from zero to: it's a bit \\
\hline 5 & ?: & [heh heh ] \\
\hline 6 & Aarto: & ((sits down)) From zero to good morning. \\
\hline 7 & ?: & heh heh heh $=$ \\
\hline 8 & Colin: & $=(($ looks around the room while talking $))$ Let's see now, are we all: all here? (1.6) \\
\hline 9 & & As $(($ person 1$))$ is still missing but he was called off to ((person 2$))$. ((stands up \\
\hline 10 & & and walks away)) And er, at least close the doors. \\
\hline 11 & & $\begin{array}{l}\text { ((15 seconds pause, Chair walks away to close the doors and back; some } \\
\text { participants are shuffling papers; sounds of door closing }))\end{array}$ \\
\hline 12 & Colin: & Well, you all know that times are changing if you look at the: ((he continues)) \\
\hline
\end{tabular}

Excerpt 2 demonstrates the opening sequence of SM1 involving five Hong Kong Chinese business professionals. The participants were informed in advance that the meeting would be conducted in English. Prior to line 1, the participants have asked the researcher questions relating to the case scenario. The language used in this section is the participants' native language - Cantonese. In line 1, the researcher instructs Cecilia, who has been selected to be the meeting chair, that she can start the meeting in English whenever she feels ready. In line 5, Cecilia first declares the meeting to start in Cantonese and then switches to English to greet and welcome the participants. In this excerpt, the declaration in line 5 and the switch of language from line 7 onwards successfully mark the transition from the pre-meeting section to the meeting section. The pauses in lines 6 and 8 show the other participants' orientation to the convention that the speaking right is controlled by Cecilia.

Excerpts 1 and 2 illustrate that the opening sequences in the two types of meetings are similar in some aspects but different in the other aspects.

Similarities in meeting openings. Three similar features are observed. First, in both types of meetings, an opening is enacted by the chair and is accomplished through a sequence of actions rather than one single turn. Second, the other meeting participants also play important roles in the opening by showing their readiness for the meeting through not engaging in any conversation (line 11 in Excerpt 1 and line 4 in Excerpt 2). Third, both openings start with a topic transitional marker (well in Excerpt 1 and so in Excerpt 2), followed by an explicit reference to a meeting-related item (Excerpt 1) or an explicit start declaration (Excerpt 2). This finding is consistent with what has been reported in the literature about formal meetings in face-to-face settings (e.g., Boden, 1994; Chan, 2008; Nielsen, 2013).

Differences in meeting openings. The difference in meeting openings lies in the sequential position of a topic transition marker. In AMs, a marker takes place at the boundary between the pre-meeting section and the meeting section as illustrated in Excerpt 1 (line 12), whereas in SMs, a marker occurs after the researcher has handed over the speaking floor to the chair (line 1 in Excerpt 2). In other words, in an AM, the chair needs to identify the appropriate time to start the meeting and uses various verbal and non-verbal strategies to signal his/her intention to start the meeting. However, these verbal and non-verbal signals are absent in the SMs because the chair of an SM starts the meeting only after he/she is instructed to do so. The researcher's instruction is also heard by the other participants and prepare them for the meeting to start.

\section{Agenda Management}

Similarities and differences are observed in agenda management. Similarities include (1) the agenda and objectives of the meeting are likely to be mentioned soon after the meeting opening, and (2) the order of the items to be discussed in the meeting is generally guided by the meeting agenda (in AMs) or the questions on the case scenario (in SMs). However, how strictly the meeting discussion follows the agenda or case scenario varies between the two types of meetings.

Similarities in agenda management. In one of the AMs and one of the SMs, the meeting chairs stated the meeting objectives soon after declaring the meeting opening. The ways the chairs formulate the objective appear to be similar. 
Excerpt 2. Opening sequence of simulated meeting 1 (SM1)

\begin{tabular}{|c|c|c|}
\hline 1 & Researcher: & ((to Cecilia)) 咁你覺得開始就可以用英文開始得家喇 \\
\hline & & $\begin{array}{l}\text { So when you feel you're ready you can start by conducting the meeting in } \\
\text { English. }\end{array}$ \\
\hline 2 & Cecilia: & $\begin{array}{l}\text { 哦 好呀 } \\
\text { Oh okay }\end{array}$ \\
\hline 3 & & $\begin{array}{l}\text { ( }(9 \text { turns omitted during which some participants and the researcher make } \\
\text { comments on the recorder)) }\end{array}$ \\
\hline 4 & & $(1.0)$ \\
\hline 5 & Cecilia: & $\begin{array}{l}\text { er:: 噉- 噉開始啦. } \\
\text { er:: So-So let's get started }\end{array}$ \\
\hline 6 & & $(0.5)$ \\
\hline $\begin{array}{l}7 \\
8\end{array}$ & Cecilia & $\begin{array}{l}\text { er, Good afternoon everybody? em, } \\
\text { (1.3) }\end{array}$ \\
\hline $\begin{array}{l}9 \\
10\end{array}$ & Cecilia: & $\begin{array}{l}\text { er I'm so sorry that em: er: I think everyone would know that our: er one of the } \\
\text { pilot product, er Easyfix er .hh has a great impact er outside in recent days? ((she } \\
\text { continues)) }\end{array}$ \\
\hline
\end{tabular}

Excerpt 3 shows how Calvin, the chair of AM1, sets the meeting objective. He first points out that they are under time constraints, and then indicates the purpose of the meeting is to develop a page plan for the issue number four, and lastly explicitly expresses his desire for a creative meeting.

Likewise in SM1, Cecilia also explicitly indicates her expectation of the meeting soon after the opening (Excerpt 4). She describes the situation the company is facing (line 1) and points out the task the participants need to achieve by the end of meeting (lines 2-4). The mentioning of the press conference in line 5 can be interpreted as an implicit indication of time constraints the participants are facing. She then asks Daisy to give opinions, selecting Daisy as the next speaker (lines 6-7).

Another similarity observed across AMs and SMs is the important role that the agenda (in the cases of AMs) or the information sheet (in the cases of SMs) played in determining what to be discussed in the meetings and in what order. In AMs, direct reference to the agendas can be made by the chairs (Excerpt 5) and the participants (Excerpt 6) to decide what to be discussed and when to discuss them.

Similarly, in the two SMs, the meeting participants often refer to the information sheet to guide their discussion in relation to the US and Asian markets. Although there could be different ways to structure the SMs, in the two SMs (as well as the other SMs in our corpus), the two markets are dealt with one by one and in the same order as presented in the information sheet, i.e., the US market first. That means although the case description does not specify the order of discussion in the simulation, the participants of the SMs are inclined to structure their discussion according to the order of questions stated in the information sheet. This suggests that the participants treated the questions as something equivalent to the meeting agenda.

The analysis reveals that the meetings are structured according to the agenda or the information sheet. However, how strictly the agenda management is controlled by the chair in accordance to the pre-planned agenda or information sheet varies across the two types of meetings, as presented in the following subsection.

Differences in agenda management. While in all four meetings, the chairs are dominant in agenda management activities, they differ in the degree of control. The two chairs in AMs tend to follow the agenda more strictly than SMs chairs. Excerpt 7 is provided for illustration.

Excerpt 7 demonstrates how the chair of AM1 controls the agenda topics. Calvin's turn in lines 1-5 signals that (1) the participants are under time pressure and (2) the meeting discussion would follow what they had discussed in the preparatory meeting. However, in lines 7-9 Roosa intends to bring up a new idea for discussion, to which Calvin responded with a suggestion that the topic be discussed later (line 12).

The language that Calvin used in rejecting Roosa's request appears to be rather assertive and bold. Although his utterances in lines 9 and 11 are formulated in question forms, falling intonation is used, making the utterances sound like statements 
Excerpt 3. Setting meeting objectives in authentic meeting 1 (AM1)

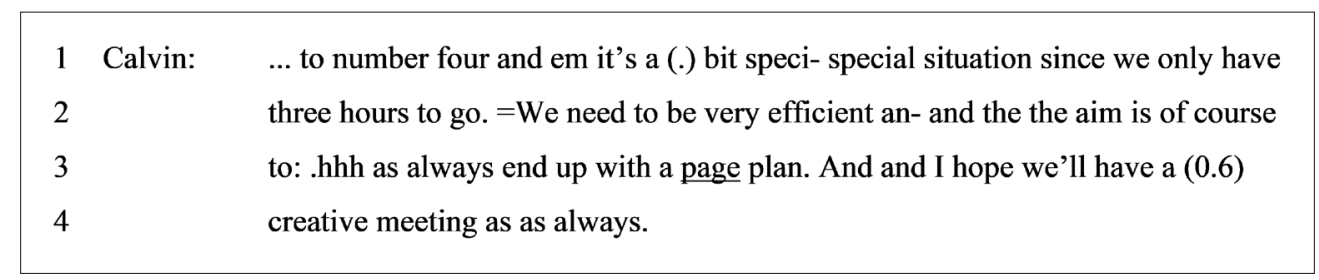

Excerpt 4. Setting meeting objectives in simulated meeting 1 (SM1)

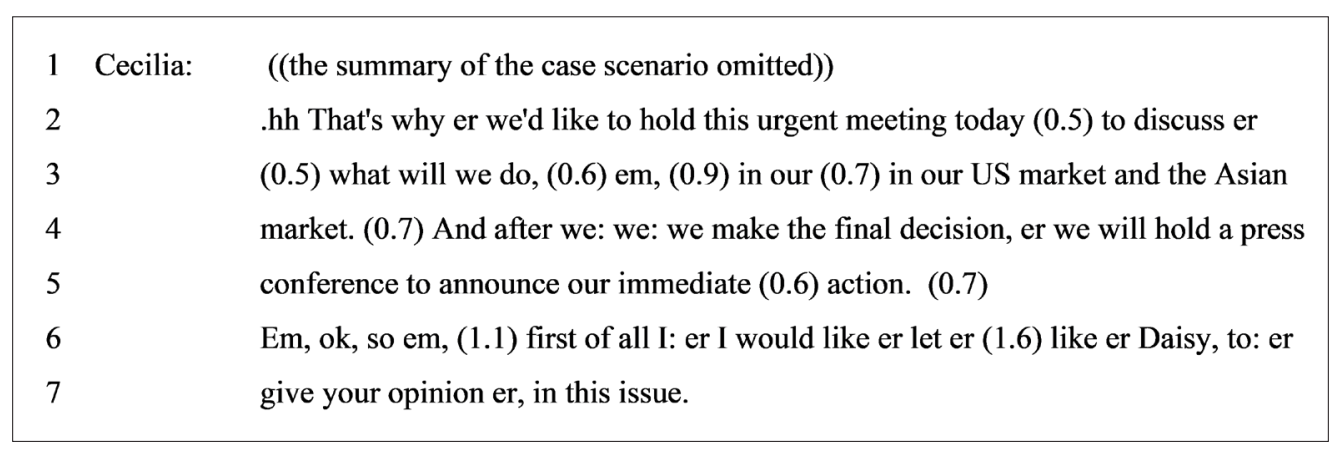

Excerpt 5. Agenda management in authentic meeting 1 (AM1) by the chair

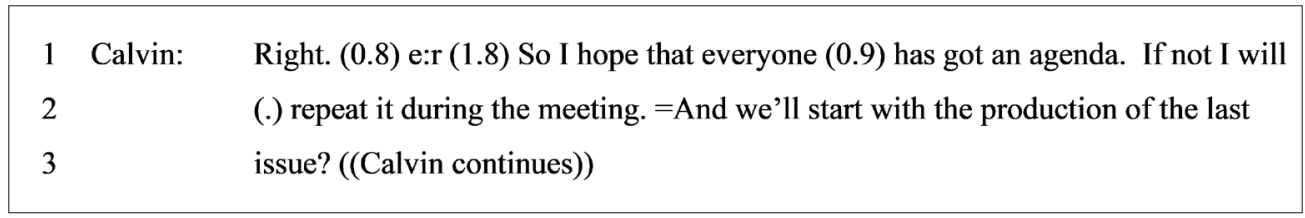

Excerpt 6. Agenda management in authentic meeting 2 (AM2) by a participant

\begin{tabular}{|lll|}
\hline 1 & Patrik: & Very shortly a f- few questions er because er er er we have er one (0.4) er (0.4) \\
2 & pro- service project going on. or just started er on- on- on corporate customer \\
3 & relations. =but we have another (.) you know point there in the agenda. =So I er I \\
4 & leave it er more in th::e main body of information for that.
\end{tabular}

rather than real questions. In line 15, he uses a let's construct which is commonly used in giving directives (Vine, 2004). In lines 18-19, in addition to selecting Karl as the next speaker, he specifies the content of Karl's turn, that is what and why Karl would like to do for the new issue. Calvin's choice of discursive strategies is not questioned or challenged by other participants, showing their recognition of Calvin's legitimacy in controlling the agenda.

In SMs, the chairs seldom employ assertive discursive strategies or specify the content of the next turn when selecting the next speaker. One example is lines 6-7 in Excerpt 4, in which Cecilia instructs Daisy to give her opinion: "Em, ok, so em, (1.1) first of all I: er I would like er let er (1.6) like er Daisy, to: er give your opinion er, in this issue." Unlike Calvin in Excerpt 5, Cecilia does not specify the content of Daisy's turn. Although Cecilia delivers her directive in a "I would like someone to do something" construct which to a certain extent displays an entitlement to issue the directive (Curl \& Drew, 2008), the pauses, stretches, and fillers (ers, ems) make the directive sound like less assertive and imposing (Vine, 2004).

\section{Turn Allocation}

Turn allocation is the third meeting chairing activity we are examining. Similar to the other activities, similarities and differences are observed.

Similarities in turn allocation. Our data shows that both types of meetings exhibit a mixture of chair-controlled turn allocation (in bold face) and participant-self-selected turn allocation (in bold italics) Excerpt 8 from an SM is presented as an illustration. Nela is the meeting chair. Lines 1-2 illustrate a turn transition by the chair-controlled turn allocation while lines 9 and 12 illustrate turn transitions by the speaker's self-selection. Such 
Excerpt 7. Agenda management in authentic meeting 1 (AM1)

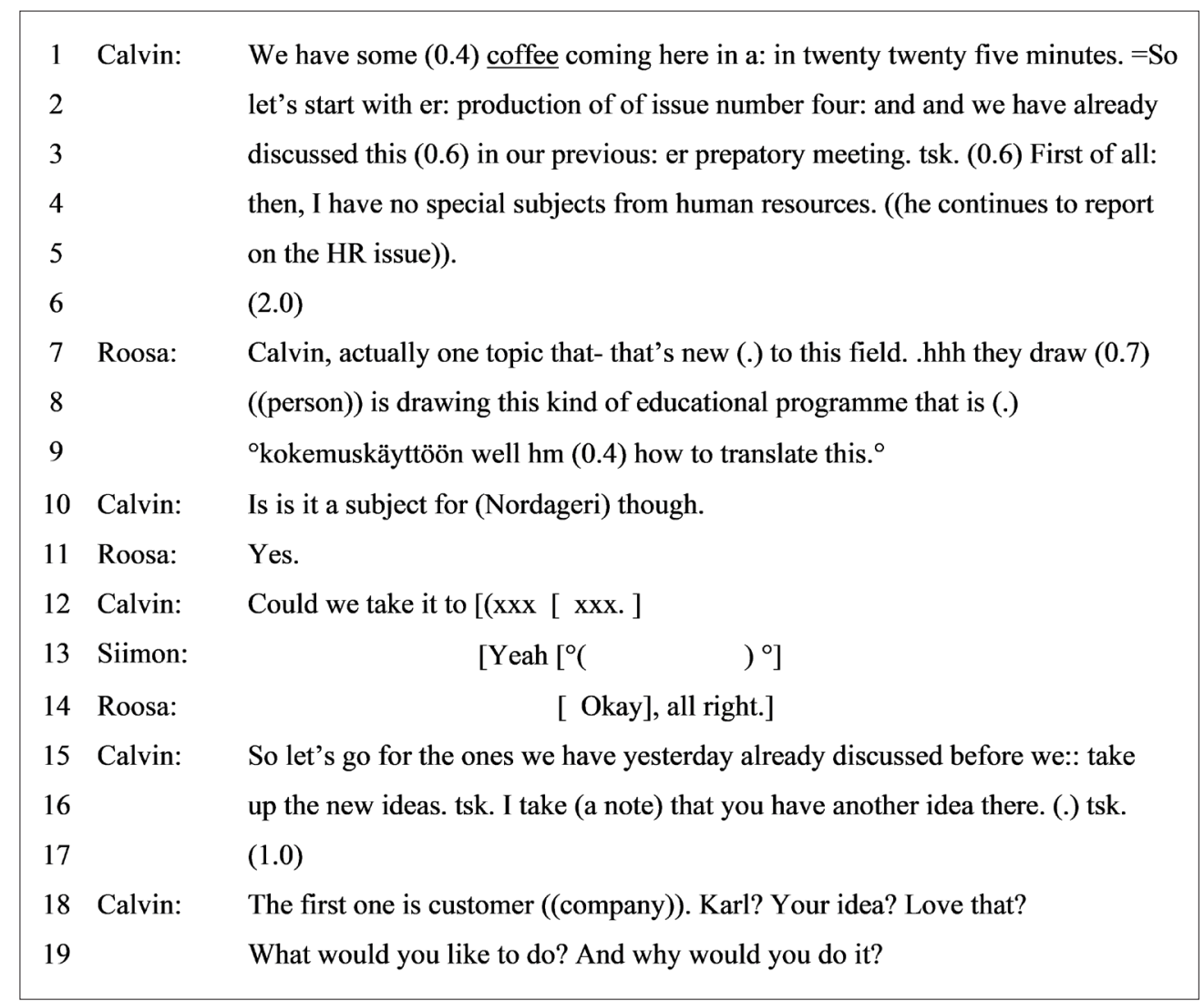

Excerpt 8. Turn allocation in simulated meeting 2 (SM2)

\begin{tabular}{|c|c|c|}
\hline 1 & Nela: & May I ask maybe Qiang to give [us his opinion?] \\
\hline 2 & Qiang: & [Yeah. (.) I- I- ] I think $C$ is a reasonable \\
\hline 3 & & choice. (1.0) And I think we should start the investigation? (0.6) of the reason \\
\hline 4 & & why it caused so many deaths. \\
\hline 5 & & ((Qiang continues to propose that they should do the study themselves)) \\
\hline 6 & & $(1.4)$ \\
\hline 7 & Nela: & $\mathrm{Mm}$ \\
\hline 8 & & $(1.2)$ \\
\hline 9 & Dave: & I mean they also made tests before. (0.3) before selling it. \\
\hline 10 & & $=\mathrm{I}$ just think there are some- somebody suddenly saying: your your product is \\
\hline 11 & & dangerous? (0.5) and you say oh god now I have to stop it. \\
\hline 12 & Gang: & no it's dangerous to the other people. heh heh heh heh heh \\
\hline 13 & & ((smiling voice)) it's dangerous to other people \\
\hline 14 & & ((Gang continues to provide justification for his remarks)) \\
\hline
\end{tabular}

combinations of turn allocation methods are common in both types of meetings.

Differences in turn allocation. Differences are observed in the chairs' choices of "current-speaker selects next" techniques
(Sacks et al., 1974) when allocating turns in the AMs and SMs. Such techniques can be categorized into explicit addressing methods and tacit addressing methods (Hayashi, 2013). Explicit addressing methods found in our meetings include using the 
next speaker's name (e.g., Karl), eye-gazing, and hand gestures. Tacit addressing methods include initiating a question related to the prior turn (e.g., South Street you said?) and selecting a group of participants (e.g., Shall we listen to the gentlemen?). In our study, both addressing techniques are used by the chairs in the four meetings but relatively speaking the chairs in AMs tend to use explicit methods more frequently. Moreover, even when explicit methods are used, the chairs in SMs tend to formulate their turn allocations in question forms such as "How about Nina?" and "may I ask maybe [sic] Qiang to give us his opinion?". Such formulations are not common in AMs where formulations such as "okay Kerkko." and "alright, next idea ... Liam." are frequently found. Relatively the former formulations sound less direct than the latter ones (Holmes \& Stubbe, 2015; Vine, 2004).

\section{Meeting Closings}

The meeting closing is the fourth meeting chairing activity examined in this study. In AMs, the meeting closings are initiated when all of the agenda items are discussed while in SMs, the meeting closings take place when the required tasks have been accomplished.

Similarities in meeting closings. The formulations of the meeting closings are similar across the two types of meetings. They are either formulated in explicit declaration (e.g., "We can end the ... meeting" in AM1 and AM2) and/or an expression of appreciation (e.g., "Okay thank you" in AM1, SM1 and SM2). The two formulations have been repeatedly reported in the literature on meeting closings (e.g., Boden, 1994; Chan, 2008; Nielsen, 2013). Due to space constraints, we use one excerpt (Excerpt 9) from an SM to illustrate the closing sequences in the four meetings.

Difference in meeting closings. The only difference in the two types of meetings is observed after a meeting is adjourned. In an AM, the participants engage in small talk soon after the meeting is adjourned. However, in an SM, the researcher will appear again to give further instructions regarding the data collection (e.g., to ask the participants to fill in a questionnaire).

In sum, RQ1 examines how the four chairing activities are accomplished in AMs and SMs and identifies similarities and differences in the enactment of these activities in the two types of meetings. Of the chairing activities being studied, many similar characteristics are found in both types of meetings. Specifically, each of the meetings contains an opening sequence and a closing sequence which mark the two boundaries of the meeting section. Within the boundaries, the participants show their adherence to the meeting conventions that one speaks at a time and that the meeting chair is entitled to control over the agenda and turn allocation. The progress of the discussion is guided by the agenda (in AMs) or the case scenario (in SMs).
Akin to many real business meetings, turn-taking in the SMs is regulated by a mixture of turn allocation systems, i.e., the allocation of speakership is coordinated by the designated chair or collaboratively managed by the meeting participants (Asmuss \& Svennevig, 2009). Lastly, the "current speaker selects next" techniques are used in allocating the speakership.

Differences of the chairing activities are also observed in the two types of meetings. Particularly, we found that the SMs are preceded and followed by the researcher's talk. Before the meeting opening in an SM, the researcher welcomes the participants, gives instructions relating to the simulation, answers questions from the participants if any, and lastly hands over the floor to the participants. The researcher reappears after the closing of the SM to thank the participants and gives additional instructions relating to the simulation. Consequently, in SMs, chairs do not need to signal their intention to start the meetings as chairs in AMs do before declaring the start of their meeting. After a SM is adjourned, all participants remain seated whereas participants in AMs tend to stand up and get ready to depart. In terms of agenda management, AM chairs are likely to manage the agenda more strictly. When allocating turns, SM chairs use tacit addressing methods more frequently while the AM chairs tend to use more frequently explicit addressing methods.

Although differences are observed, prior research reveals that variation in the enactment of meeting chairing activities is common in authentic business meetings (Asmuss \& Svennevig, 2009). For instance, a subtle and implicit manner of formulating the chairing activities is observed in a senior management meeting chaired by a less senior person (Pomerantz \& Denvir, 2007) and in informal meetings which do not have designated chairs (Angouri \& Marra, 2010). In real business contexts, there is a room for variation in actual practices of the chairing activities, contingent on the contextual factors of a meeting and on the other participants' responses (Asmuss \& Svennevig, 2009; Chan, 2008, 2017; Schnurr \& Chan, 2011).

Arguably, in meeting chairing activities, the differences between AMs and SMs may not be as distinct as reported in previous studies that involved short interactional exchanges (Ewald, 2012) or employed trainees or actors who did not know how to adequately perform the assigned task (Stokoe, 2013; White \& Casey, 2016; we will return to this point in the section on RQ2). It is reasonable to conclude that the communication behaviors observed in the SMs and the AMs may share a considerable degree of similarities in terms of what the participants do in meeting chairing activities. However, the variation in how the meeting activities are linguistically accomplished suggests that the SMs may not reflect the communication patterns of meeting chairing at a micro linguistic level. In the following section, we 
Excerpt 9. Meeting closing in simulated meeting 1 (SM1)

\begin{tabular}{lll}
\hline 1 & Cecilia: & Yeah, we- we will tell the media we are doing many many cautious measures, to \\
2 & & er to er to make the Easyfix er er er to prove the Easyfix is a (.) safety product (.) \\
3 & & safety drugs $(0.5)$ er in the market. \\
4 & & $(0.5)$ \\
5 & Bruce: & Yeah \\
6 & Cecilia: & Yeah and to let the: all the: um the end user, customer know that er er we are the \\
7 & & (compliance the ethnical and) high level (0.6) ethical company. \\
8 & Bruce: & Yap \\
9 & Daisy: & ((nods)) \\
10 & Cecilia: & Ok. So, ok? That's good, ok? em:: (.) \\
11 & & ((looks around the participants) $)$ ok? \\
12 & Some: & ((nods)) \\
13 & Cecilia: & Thank you for your time. OK. \\
14 & Nancy: & Thank you very much. \\
15 & & (5.0) \\
16 & & ((Cecilia requests for the recorder to be switched off))
\end{tabular}

build on the above findings and answer RQ2.

\section{R02: Under What Settings Would Simulated Data be Com- parable to Authentic Data?}

This section discusses possible settings under which simulated data is comparable to authentic data. In so doing, we first present two factors that may contribute to the similarities, and then explore three factors that are attributable to the differences.

\section{Settings Where Simulated and Authentic Data Likely to be Comparable}

One of the two factors that are likely to account for the compatibility across the two types of meetings is the ritual and formulaic nature of business meetings (Chan, 2008). Regardless of organizational types and locations, meetings are routinely practiced in the business world and possess a wide range of shared characteristics in terms of meeting openings and closings, turn allocation, and agenda management (Angouri \& Marra, 2010; Asmuss \& Svennevig, 2009; Boden, 1994). It is reasonable to assume that experienced business professionals are aware of the general meeting conventions and possess knowledge of enacting the meeting chairing activities.

The second factor is the recruitment of experienced business professionals as research participants. All of the participants in the SMs possessed more than five years working experience, held managerial positions, and had chairing meetings as part of their job responsibilities. Although the SM participants were provided with a hypothetical case scenario and the assigned roles differ from their own, the meetings were not scripted. In order to accomplish the assigned task, the SM participants had to apply authentic communication strategies as those used in real-life business meetings. The interaction in each SM meeting was locally managed by the meeting participants. In this sense, it is plausible to consider such simulated data as a kind of naturalistic data and share many similarities to business meetings collected in authentic settings.

This finding suggests that when a simulation involves a routine activity in the real business world and is conducted by business professionals with relevant experience in the activity under research (e.g., decision-making meeting, negotiation) the participants would know how to adequately and genuinely accomplish the activity (e.g., Kernbach, Eppler, \& Brescianni, 2015; Planken, 2005). These studies, together with the present study, have revealed that simulated data can be used as an alternative to authentic data when the participants have relevant experience with the communication activity being studied.

\section{Settings Where Simulated and Authentic Data Unlikely to be Comparable}

Three contextual factors, including the situated context, the meeting chair's organizational role, and the relationship among participants, are discussed to explicate the differences. 
The situated context. A main difference between the AMs and the SMs is that the AMs are situated in an authentic setting while the SMs are situated in a setting that was set up for research purposes. In AMs, it is the chair who identifies the appropriate time to open/close a meeting and shift the participants' orientations from/to a turn-taking system for the pre-meeting section to/from a controlled turn-taking system for the meeting. However, in an SM, the meeting opening is commonly preceded by a section where the researcher welcomes the participants and provides information about the project and the scenario. Likewise, when the meeting is adjourned, the participants wait for further instructions from the researcher. It is only after the researcher has declared the end of the simulation, the participants shift their orientation to a conversation-like turn-taking system. The differences observed in this study support what has been reported in the literature that the SM participants are aware of such contextual factors and have adjusted their behavior accordingly (Ewald, 2012; Stokoe, 2013).

The meeting chair's organizational roles. Arguably, when managing agenda and turn allocation, the chairs are in fact delivering directives by asking the selected participant to speak or not to speak on a particular topic. Curl and Drew (2008) assert that the formulation of a directive demonstrates the speaker's orientation to his or her entitlement to deliver the directive. That is, the chair holds a special position in the meeting and has the legitimacy or entitlement to enact the chairing activities (Asmuss \& Svennevig, 2009; Boden, 1994). We expect that the chairs of AMs and SMs demonstrate a similar degree of entitlement when selecting the next speaker or setting the agenda.

On the contrary, one main difference observed in the present study is the language used in formulating the activities related to agenda management and turn allocation. The chairs in AMs tend to use more frequently assertive strategies in agenda management and explicit methods of addressing in turn allocation (Excerpt 7), whereas the SMs chairs tend to use implicit and mitigated strategies (such as using hedges and questions shown in Excerpts 4 and 8). This observation suggests that the SMs chairs do not orient to their entitlement in meeting chairing in a similar way as the AMs chairs do.

We speculate that this phenomenon may be attributed to the organizational roles that the chairs are due to enact. In the present study, the AMs chairs are the team leaders of the meeting participants; whereas, the SMs chairs are assigned roles of equal status (as members of the directors' board). Thus, the SMs chairs do not seem to have the power and entitlement as the AMs chairs do. Consequently, in formulating the chairing activities, the SMs chairs display their orientation to low entitlement and high contingency (Curl \& Drew, 2008) through their choice of communication strategies. Similar behaviors can be observed in authentic meetings as reported by Pomerantz and Denvir (2007) and Angouri and Marra (2010).

Relationship among participants. The differences in the chairs' choices of linguistic strategies can also be attributed to the relationship among the meeting participants. Working in the same organization, the AM participants have formed a community of practice (Wenger, 1998), and therefore, the language tends to be more "collegial" (Holmes, 2000), as reflected through the frequent occurrences of small talk and humor (Du-Babcock, 2013). In contrast, the SMs participants were brought together the first time specifically for the meeting; consequently, the SMs participants have not yet formed a community of practice. This may have affected the participants' communication behaviors (Wenger, 1998 ) and may account for the frequent use of mitigation and implicit language in formulating the meeting chairing activities.

Since the impact of various contextual factors on the participants' communication behaviors is evident and should not be neglected, simulated data may not be suitable for studying activities that are highly dependent on contextual factors. For example, when the activity being studied can be accomplished in a short period of time (e.g., direction giving; Ewald, 2012) or takes place in the onset of the activity (e.g., the opening of a business meeting [this study] or the opening of a police investigation; Stokoe, 2013), the simulated interaction may not be able to reflect the features of authentic practices.

\section{Conclusion}

This section concludes the main findings from the study, identifies the study limitations, and points out implications for future research.

While simulations are commonly used in the field of business and professional communication, there are different views towards the authenticity of simulated data. There is a lack of empirical research comparing interaction produced in simulated and authentic settings and the limited existing literature provides contradictory findings. The present study attempts to address this gap by comparing the enactment of the four meeting chairing activities in two AMs and two SMs. By adopting a moment-by-moment discourse-analytical approach, we identify the turns that are intended to perform the function of the meeting activities and compare across these two types of meetings.

Two research questions are addressed in the analysis. In relation to RQ1, our analysis and comparisons of the four chairing activities exhibit similar and different communication features across the two types of meetings. Particularly, there is a consid- 
erable degree of similarities between the two types of meetings in terms of communicative strategies used to open or close a meeting, to manage the meeting agenda, and to allocate speakership while differences are observed in the actual discourse used to accomplish these chairing activities. In RQ2, we account for the similarities in terms of the routine nature of business meetings and the use of experienced business professionals. The observed differences are attributed in terms of the participants' orientations to the meetings' contextual factors (Asmuss \& Svennevig, 2009), including the setting that an SM is embedded, the organizational roles that a meeting chair is playing, and the relationship among the meeting participants. We further argue that simulated data may be comparable to authentic data when the activity being studied is commonly practiced and when participants with relevant experience are recruited. On the other hand, simulated data may not be comparable to authentic data when a participant's choices of linguistic strategies are highly contingent upon the other participants' response and upon the context the interaction that is embedded in (e.g., Chan, 2007; Chan, Zhang, Zayts, Tang, \& Tam, 2015; Curl \& Drew, 2008).

\section{Limitations}

The use of two existing meeting corpora has limited the amount of data available for the present study. As the corpora were built for different research purposes, not all meetings are compatible and can be selected for the present study. However, the total duration of the selected meetings is about eight hours which appears to be considered acceptable for detailed discourse analysis. Moreover, as the meetings involve different purposes and topics (especially for the two AMs), it is possible that the participants' communication behavior have been affected. An attempt to minimize the impact of this limitation is to focus on four chairing activities which are commonly practiced in business meetings (e.g., Angouri \& Marra, 2010) and less influenced by contextual factors.

\section{Implications}

Building on the findings yielded from the present study, we discuss three implications for the use of simulated data in researching and teaching business and professional communication.

First, as discussed in RQ2, the similarities between authentic and simulated data provide evidence that, simulated data possesses many features of authentic data and reflects what participants do in meeting chairing. In addition to the current study, previous studies have also employed simulated data to examine, for example, topic management (Du-Babcock, 1999, 2006), decision-making (Spanjol, Tam, Qualls, \& Bohlmann, 2011), and negotiation (Planken, 2005). These studies show that simulated data can constitute valuable data for researching business and professional communication practices at macro levels, or when the researcher intends to focus on a certain aspect of the situation and wish to control as many variables as possible (Baxter, 2015; Félix-Brasdefer, 2010; Sekaran \& Bougie, 2014). As Planken (2012) rightly points out, the business environment has become increasingly complex and business communication should best be researched with multiple approaches. Simulated data, when used in combination with mixed methods (e.g., quantitative and qualitative methods), "can offer additional insights with regard to the artefact, issue or question being studied" (Planken, 2012, p. 35; see also Beebe \& Cummings, 1996; Ulijn, 2000).

Second, the differences in actual linguistic enactment of meeting chairing activities in the two types of business meetings remind us that simulated data should be used with caution, especially for studies from linguistic perspectives. Due to the complex and dynamic nature of interaction, authentic data is highly recommended for such research. Moreover, it is important to consider the impact of the embedded context throughout the process of designing and analyzing a simulation. Our study, as well as Ulijn (2000) and Kernbach et al. (2015), reveals that the participants recruited for a simulated study should have relevant experience with the concerned communication activity because otherwise the participants may not know how to adequately enact the assigned role/task in the simulated context.

Lastly, the study also has implications for the use of simulations in teaching business and professional communication. Simulations have become a popular pedagogical tool in professional training. Previous studies have shown that the use of simulations enable students to deal with real world situations in a safe and supportive environment and are effective in facilitating students to develop the target skills (e.g., Cuhadar \& Kampf, 2014; Hodgson, Lamson, \& Feldhousen, 2007). The current study has demonstrated that on the one hand simulated data can reflect communicative strategies people use in authentic situations; yet one the other hand there are discrepancies in how these strategies are actually implemented due to various contextual factors. Similar findings are reported in Stokoe (2013) and Dannels (2003). In order to "give students a meaningful professional experience in the classroom" (Dannels, 2003, p. 165), teachers, when incorporating a simulation scenario into the curriculum, should carefully analyze the scenario and design relevant activities and instructions in accordance with course objectives, and help students develop a sensitivity to possible contingencies in real-life situations. 


\section{Acknowledgements}

The present study was financially supported by three research grants, (1) the GRF (Project No. 9041451) funded by the Hong Kong Special Administrative Region, (2) the CLASS Research Writing Fund (Project No. 9618006) funded by City University of Hong Kong, and (3) the Scientific Research Initiation Grant (Project No.: STF17011) funded by Shantou University. We are grateful to the generosity of the funding sources. We also wish to thank Professor Emeritus Mirjaliisa Charles and her associates Professor Emeritus Leena Louhiala-Salminen as well as Dr. Anne Kankaanranta for their generosity in sharing the video recordings and preliminary transcripts of the authentic meetings.

\section{References}

Angouri, J., \& Marra, M. (2010). Corporate meetings as genre: A study of the role of the chair in corporate meeting talk. Text \& Talk, 30(6), 615-636.

Asmuss, B., \& Svennevig, J. (2009). Meeting talk: An introduction. Journal of Business Communication, 46(1), 3-22.

Atkinson, M. A., Cuff, E. C., \& Lee, J. R. E. (1978). The recommencement of a meeting as a member's accomplishment. In J. Schenkein (Ed.), Studies in the organization of conversational interaction (pp. 133-153). New York, NY: Academic Press.

Bargiela-Chiappini, F., Nickerson, C., \& Planken, B. (2013). Business discourse. Hampshire, UK: Palgrave Macmillan.

Baxter, J. (2015). Who wants to be the leader? The linguistic construction of emerging leadership in differently gendered teams. International Journal of Business Communication, 52(4), 427-451.

Beaubien, J. M., \& Baker, D. P. (2004). The use of simulation for training teamwork skills in health care: How low can you go? Quality and Safety in Health Care, 13(suppl 1), i51-i56.

Beebe, L. M., \& Cummings, M. C. (1996). Natural speech act data versus written questionnaire data: How data collection method affects speech act performance. In S. M. Gass, \& J. Neu (Eds.), Speech acts across cultures: Challenges to communication in a second language (pp. 65-86). Berlin, Germany: Mouton de Gruyter.

Ben-Zvi, T., \& Carton, T. C. (2008). Applying bloom's revised taxonomy in business games. Develop Business Simulation Experiential Learning: Proceedings of the Annual ABSEL Conference (Vol. 35, pp. 265-272).

Boden, D. (1994). The business of talk: Organizations in action. Cambridge, UK: Polity Press.

Chan, A. (2007). Same context, different strategies: A company director's discourse in business meetings. Journal of Asian Pacific Communication, 17(1), 61-81.

Chan, A. (2008). Meeting openings and closings in a Hong Kong company. In H. Sun, \& D. Z. Kádár (Eds.), It's the dragon's turn: Chinese institutional discourses (pp. 181-229). Bern, Swiss: Peter Lang.

Chan, A. (2017). Constructing a "competent" meeting chair: A study of the discourse of meeting chairing in a Hong Kong workplace. In D. Van de Mieroop, \& S. Schnurr (Eds.), Identity struggles: Evidence from workplaces around the world (pp. 39-55). Amsterdam, The Netherlands: John Benjamins.

Chan, A., Zhang, W., Zayts, O., Tang, M. H. Y, \& Tam, W. K. (2015). Directive-giving and grammatical forms: Mitigation devices in a medical laboratory setting. Chinese Languages and Discourse, 6(2), 133-161.

Chilcott, J. D. (1996). Effective use of simulations in the classroom. Creative Learning Exchange. Retrieved from http://static. clexchange.org/ftp/documents/implementation/IM199601EffectiveUseOfSims.pdf

Cook, D. A., Erwin, P. J., \& Triola, M. M. (2010). Computerized virtual patients in health professions education: A systematic review and meta-analysis. Academic Medicine, 85(10), 1589-1602.

Cooper, S., Cant, R., Porter, J., Bogossian, F., Mckenna, L., Brady, S., \& Fox-Young, S. (2012). Simulation based learning in midwifery education: A systematic review. Women Birth, 25(2), 64-78.

Cuhadar, E., \& Kampf, R. (2014). Learning about conflict and negotiations through computer simulations: The sase of PeaceMaker. International Studies Perspectives, 15(4), 509-524.

Curl, T. S., \& Drew, P. (2008). Contingency and action: A comparison of two forms of requesting. Research on Language and Social Interaction, 41(2), 129-153.

Dannels, D. P. (2003). Teaching and learning design presentations in engineering: Contradictions between academic and workplace activity systems. Journal of Business and Technical Communication, 17(2), 139-169.

Du-Babcock, B. (1999). Topic management and turn-taking in professional communication: First versus second-language strategies. Management Communication Quarterly, 12(4), 544-574.

Du-Babcock, B. (2006). An analysis of topic management strategies and turn-taking behavior in Hong Kong bilingual environment: The impact of culture and language use. Journal of Business Communication, 43(1), 21- 42.

Du-Babcock, B. (2013). English as business lingua franca: A comparative analysis of communication behavior and strategies in Asian and European contexts. Ibérica, 26, 99-130.

Du-Babcock, B., \& Babcock, R. (2000). Adapting an American-based simulation to a Hong Kong classroom. Business Communication Quarterly, 63(2), 9-40.

Du-Babcock, B., \& Tanaka, H. (2013). A comparison of the communication behaviors of Hong Kong Chinese and Japanese business professionals in intracultural and intercultural deci- 
sion-making meetings. Journal of Business and Technical Communication, 27(3), 263-287.

Eisenstein, M., \& Bodman, J. (1993). Expressing gratitude in American English. In G. Kasper, \& S. Blum-Kulka (Eds.), Interlanguage pragmatics (pp. 64-81). New York, NY: Oxford University Press.

Ewald, J. D. (2012). Can you tell me how to get there?: Naturally-occurring versus role play data in direction giving. Pragmatics, 22(1), 79-102.

Faira, A. J., Hutchinson, D., Wellington, W. J., \& Gold, S. (2009). Developments in business gaming: A review of the past 40 years. Simulation \& Gaming, 40(4), 464-487.

Félix-Brasdefer, J. C. (2010). Data collection methods in speech act performance. In A. Martinez-Flor, \& E. Usó-Juan (Eds.), Speech act performance: Theoretical, empirical and methodological issues (pp. 41-56). Amsterdam, The Netherlands: John Benjamins.

Firth, A. (1995). Introduction and overview. In A. Firth (Ed.), The discourse of negotiation: Studies of language in the workplace (pp. 3-39). Oxford, UK: Pergamon.

Guffey, M. E., \& Du-Babcock, B. (2010). Essentials of business communication (2nd ed.). Singapore: Cengage Learning Asia.

Handford, M. (2010). The language of business meetings. Cambridge, UK: Cambridge University Press.

Hayashi, M. (2013). Turn allocation and turn sharing. In J. Sidnell, \& T. Stivers (Eds.), The handbook of conversation analysis (pp. 167-190). Chichester, UK: Wiley-Blackwell.

Hertel, J. P., \& Millis, B. J. (2002). Using simulations to promote learning in higher education: An introduction. Sterling, VA: Stylus.

Hodgson, J. L., Lamson, A. L., \& Feldhousen, E. B. (2007). Use of simulated clients in marriage and family therapy education. Journal of Marital and Family Therapy, 33(1), 35-50.

Holmes, J. (2000). Doing collegiality and keeping control at work: Small talk in government departments. In J. Coupland (Ed.), Small talk (pp. 32-61). Harlow, UK: Pearson Education.

Holmes, J., \& Stubbe, M. (2015). Power and politeness in the workplace: A sociolinguistic analysis of talk at work (2nd ed.). London, UK: Routledge.

Hughes, T., O’Regan, N., \& Wornham, D. (2008). The credibility issue: Closing the academic/ practitioner gap. Strategic Change Journal, 17(7-8), 215-233.

Kasper, G. (2000). Data collection in pragmatics research. In H. Spencer-Oatey (Ed.), Culturally speaking: Managing rapport through talk across cultures (pp. 316-341). London, UK: Continuum.

Kernbach, S., Eppler, M. J., \& Brescianni, S. (2015). The use of visualization in the communication of business strategies: An experimental evaluation. International Journal of Business Communication, 52(2), 164-187.

Lateef, F. (2010). Simulation-based learning: Just like the real thing. Journal of Emergent Trauma Shock, 3(4), 348-352.
Lorello, G. R., Cook, D. A., Johnson, R. L., \& Brydges, R. (2014). Simulation-based training in anaesthesiology: A systematic review and meta-analysis. British Journal of Anesthesia, 112(2), 231-245.

Mirivel, J. C., \& Tracy, K. (2005). Premeeting talk: An organizationally crucial form of talk. Research on Language and Social Interaction, 38(1), 1-34.

Nielsen, M. F. (2013). "Stepping stones" in opening and closing department meetings. Journal of Business Communication, 50(1), 34-67.

Oittinen, T., \& Piirainen-Marsh, A. (2015). Openings in technology-mediated business meetings. Journal of Pragmatics, 85, 47-66. Planken, B. (2005). Managing rapport in lingua franca sales negotiations: A comparison of professional and aspiring negotiators. English for Specific Purposes, 24(4), 381-400.

Planken, B. (2012). The changing landscape of business communication: Developments and directions in research. In P. Heynderickx, S. Dieltjens, G. Jacobs, P. Gillaerts, \& E. de Groot, (Eds.), The language factor in international business: New perspectives on research, teaching and practice (pp. 17-40). Bern, Swiss: Peter Lang.

Pomerantz, A., \& Denvir, P. (2007). Enacting the institutional role of chairperson in upper management meetings: The interactional realization of provisional authority. In F. Cooren (Ed.), Interacting and organizing: Analyses of a management meeting (pp. 3152). London, UK: Lawrence Erlbaum.

Riedel, J. C., \& Hauge, J. B. (2011). State of the art of serious games for business and industry. In K. D. Thoben, V. Stich, \& A. Imtiaz (Eds.), Proceedings of the 17th International Conference on Concurrent Enterprising (ICE 2011). Aachen, Germany.

Sacks, H., Schegloff, E. A., \& Jefferson, G. (1974). A simplest systematics for the organization of turn taking for conversation. Language, 50(4), 696-735.

Schnurr, S., \& Chan, A. (2011). Exploring another side of co-leadership: Negotiating professional identities through face-work in disagreements. Language in Society, 40(2), 187-209.

Sekaran, U., \& Bougie, R. (2014). Research methods for business. Hoboken, NY: Wiley.

Snyder, L. G., \& Snyder, M. J. (2008). Teaching critical thinking and problem solving skills. Delta Pi Epsilon Journal, 1(2), 90-99.

Spanjol, J., Tam, L., Qualls, W. J., \& Bohlmann, J. D. (2011). New product team decision making: Regulatory focus effects on number, type, and timing decisions. Journal of Product Innovation Management, 28(5), 623-640.

Stokoe, E. (2013). The (in)authenticity of simulated talk: Comparing role-played and actual interaction and the implications for communication training. Research on Language \& Social Interaction, 46(2), 165-185.

Svennevig, J. (2011). Leadership style in managers' feedback in 
meetings. In J. Angouri, \& M. Mara (Eds.), Constructing identities at work (pp. 17-39). Hampshire, UK: Palgrave Macmillan.

Ulijn, J. (2000). Innovation and international business communication: Can European research help to increase the validity and reliability for our business and teaching practice? 1999 outstanding researcher lecture. Journal of Business Communication, 37(2), 173-187.

van der Wijst, P., \& Ulijn, J. (1995). Politeness in French/Dutch negotiation. In K. Ehlich, \& J. Wagner (Eds.), The discourse of business negotiation (pp. 313-348). Berlin, Germany: Mouton de Gruyter.
Vine, B. (2004). Getting things done at work: The discourse of power in workplace interaction. Amsterdam, The Netherlands: John Benjamins.

Wenger, E. (1998). Communities of practice: Learning, meaning and identity. Cambridge, UK: Cambridge University Press.

White, R. (1997). Back channelling, repair, pausing, and private speech. Applied Linguistics, 18(3), 314-344.

White, S. J., \& Casey, M. (2016). Understanding differences between actual and simulated surgical consultations: A scoping study. Australian Journal of Linguistics, 36(2), 257-272.

\section{Appendix}

Appendix 1. Transcription conventions

\begin{tabular}{|ll|}
\hline$()$. & Untimed brief pause \\
$(\mathrm{n})$ & Timed pause where "n" indicates the interval measured in seconds \\
$:$ & Lengthened sound \\
- & Sudden cut off \\
& The second utterance is latched onto the first one, i.e., no gap between the \\
thh & Audible inhalations \\
$>$ word $<$ & Word uttered at a faster pace \\
$<$ word $>$ & Word uttered at a slower pace \\
Word & Stressed word \\
${ }^{\circ}$ word & The word is said softer than the surrounding talk \\
$(())$ & Transcriber's comments \\
$($ word $)$ & Word in doubt \\
$($ xxx $) /($ & Inaudible speech \\
{[} & The beginning of overlapping \\
] & The end of overlapping \\
heh & Laughter (Hah is used to represent louder laughter) \\
\hline
\end{tabular}

